\title{
NEXT GENERATION SEQUENCING - SOLVING DIAGNOSTIC DILEMMAS
}

\section{K. Pettinger, L. McKelvie, A. Breeze, I. Berry, J. Campbell, K. Johnson}

\section{Background}

Next generation sequencing encompasses:

- whole genome sequencing

- whole exome sequencing

- clinical exome sequencing

The genome is all of a person's genes. Exons are the protein coding regions of a gene and make up 1\% of a person's genome.

The exome is all of the exons in a genome.

Clinical exome sequencing relates to the exons of genes known to be associated with human disease and therefore is thought to be efficient and cost effective.

\section{Case Report}

A female infant was born at 27 weeks, prior to invasive testing, with a working diagnosis of Trisomy 18 (Edward's Syndrome) due to abnormal antenatal ultrasound findings. Postnatal examination revealed:

- Bilateral fixed talipes.

- Clinodactyly.

- Smooth philtrum

- Microstomia + fixed jaw

\section{A chest radiograph} showed rib deformity and lumbosacral abnormality.

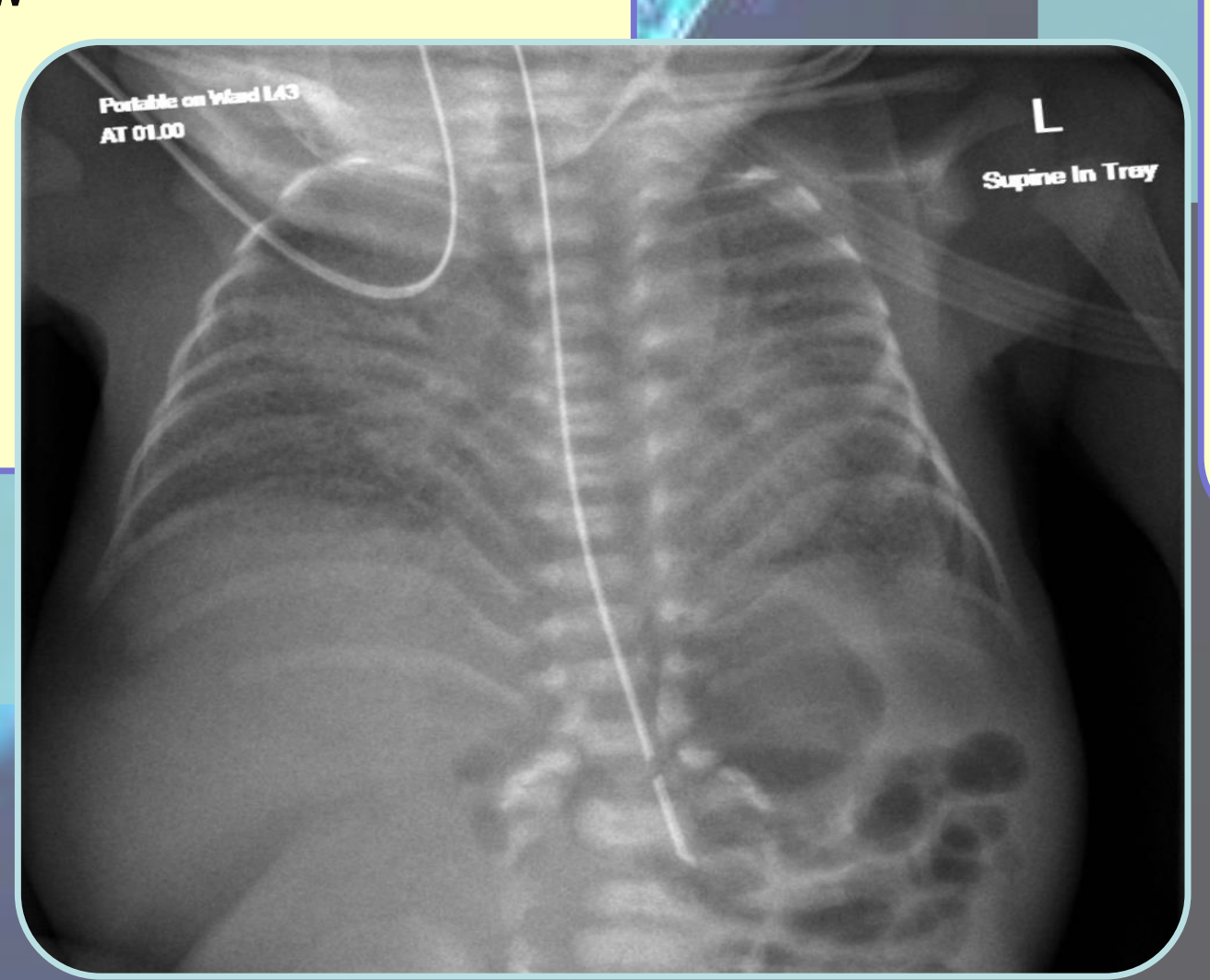

\section{Investigations}

QF-PCR was normal, refuting the presumed diagnosis of Trisomy 18. Karyotype and chromosome microarray were also normal.

Clinical exome sequencing was carried out, revealing pathogenic MHY3 mutation and a diagnosis of Freeman-Sheldon syndrome.
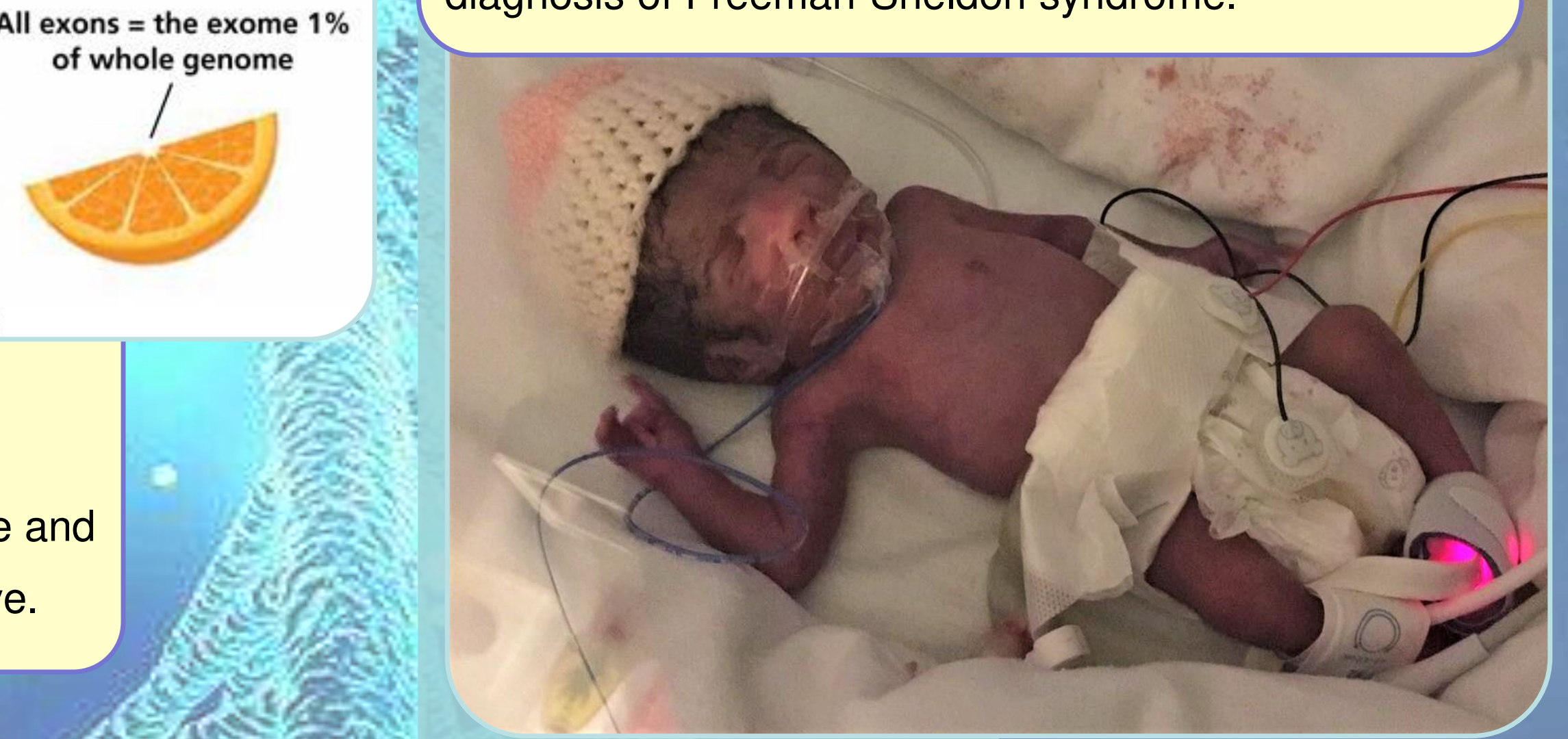

\section{Conclusions}

Next generation sequencing is being used increasingly in clinical practice, particularly to establish rare diagnoses, including in neonatal practice. It is therefore important that clinical neonatologists understand this rapidly expanding field and how they might apply such exome sequencing to solving diagnostic conundrums. Establishing the correct diagnosis enables clinicians to expand their knowledge of rare disease, and counsel families accurately about subsequent pregnancies. 